\title{
New microcogeneration with solar energy: stirling, thermal and photovoltaic systems
}

\author{
Auñón, J.A. ${ }^{1}$, Sidrach-de-Cardona, M $^{2}$, M., Marfil ${ }^{1}$, A., Gómez de la Varga, J. ${ }^{2}$ \\ ${ }^{1}$ Department of Mechanical, thermal and Fluids Engineering \\ E.T.S.I.I., Universidad de Málaga \\ Campus of Teatinos - Málaga, 29071(Spain) \\ Phone/Fax number: +0034 951952394, e-mail: jaaunon@uma.es, \\ ${ }^{2}$ Department of Applied Phisycs II \\ E.T.S.I.I., Universidad de Málaga \\ Campus of Teatinos - Málaga, 29071(Spain) \\ Phone+0034 951952299, e-mail: msidrach@ctima.uma.es
}

\begin{abstract}
.
This paper analyses the viability of a new microcogeneration system with a Stirling engine-based micro-CHP (combined heat and power) and renewable solar energy: thermal and photovoltaic system in order to supply the energy demand of an isolated home. The right sizing of solar energy systems should allow optimizing both the available solar resources and gas consumption for one specific climatological conditions.

The present work shows the first results of the experimental study of a micro-cogeneration system (micro-CHP based on the Stirling motor) supported with renewable energy. The system of self-government covers the theoretical daily consumption of a house.

In this results, the different contributions of the subsystems to the daily thermal and electric demand are displayed.
\end{abstract}

\section{Key words}

Microcogeneration, stirling engine, solar energy, photovoltaic system.

\section{Introduction}

Nowadays sustainable energy policies are reducing energy consumption in buildings and producing the required energy in a more efficient way than few years ago. Moreover, the reduction of costs of solar energy systems, especially significant in photovoltaic systems, allow cost effective alternatives to conventional energy systems.

There are technologies such as micro-cogeneration which have been improving during the last years, since it works with many functional and economic advantages over the conventional kinds of production.
Stirling engine based micro-CHP devices have been analysed during last years and are becoming a solution for supplying heating, domestic hot water (DHW) and electrical power such as I. González-Pino et al. concluded [1,2]. Valenti and Silva [3] compared the alone microCHP unit in an experimental and numerical analyses of the device. Improving the performance of a micro-CHP device is related with keeping a constant heat demand since when electricity is produced you can take advantage of the heat that is also being produced [4] and that is why "District Heating" is a trend as studied by Emmanouil Malliotakis et al. [5]. In application to energy production, Karmacharya and Putrus [6] go further in a simulation with multiple micro-generators: a micro-CHP device supported with a wind turbine and a photovoltaic panel.

The proposal system has stirling engine like novelty in cogeneration systems combined with renewable energy. Without this engine, there are many studies about cogeneration. "Trigeneration for domestic purposes in isolated areas based on hybrid RES" L. Acevedo et al. [7] is an analysis about this systems published in International Conference on Renewable Energies and Power Quality (ICREPQ'17). With focus in rural applications Jan Iwaszkiewicz et al. published “ A practical approach to the cogeneration system for rural appliances" [8]. Similar focus tan this work has the article "Design and operation of a local cogeneration plant supplying a multi-family house" published by M. Fernandez et al. [9] in this case for $9.5 \mathrm{~kW}$ electrical and $35 \mathrm{~kW}$ thermic power. Cogeneration system with thermal engine and photovoltaic was analysed by M. Dondas [10] in Fuel consumption minimization of a cogeneration system multi machines associated with a photovoltaic 


\section{Experimental facilities}

The laboratory of cogeneration in Málaga University (Fig. 1,2) has three systems for energy production and storage system.

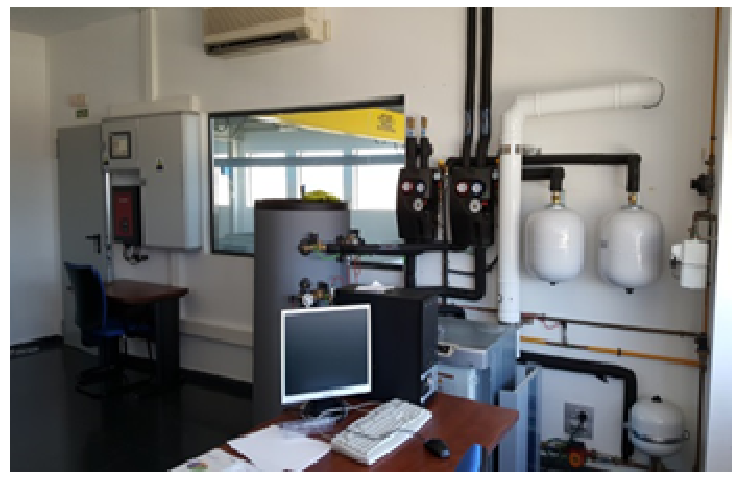

Fig. 1. Laboratory of Cogeneration.

The micro-cogeneration consists of a Whispergen EU1 Stirling micro-CHP unit. A solar thermal system with two solar collectors and one $300 \mathrm{~L}$ associated storage tank. The solar collectors are installed in a parallel circuit to the Stirling hot water production. One photovoltaic systems of $3.0 \mathrm{kWp}$ peak power with an electrical storage of $48 \mathrm{~V}$ lithium-ion battery and $10 \mathrm{kWh}$ of capacity. The entire electrical system is controlled by a photovoltaic inverter Sun Storage 1play 3TL. The electrical part of the micro-CHP unit is also connected to the inverter.

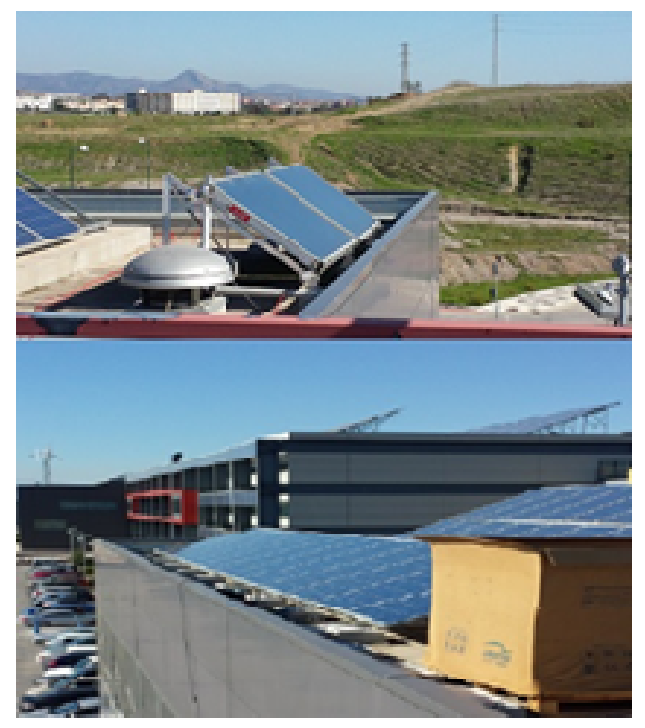

Fig.2. View of the Photovoltaic modules and thermal collectors

It is also able to connect to the grid and has the Stirling as auxiliary electric source.

The technical characteristics of the systems are summarized in table 1 .

A weather station measures real time data of the solar irradiation, ambient temperature, humidity, wind speed and direction as well as the photovoltaic module temperature.

A control system based in a PLC Mitsubishi model L02CPU-P with an interface GT2510-VTBA commands the whole system and manages the production and the activation of the loads according to a provided flowchart, this allows simulate any demand profile in electrical or thermal energy. The operating data of all the systems in real time are recorded. In Fig. 3 the diagram of the experimental system is shown.

Table 1. Technical characteristics of the system

\begin{tabular}{|c|c|}
\hline \multicolumn{2}{|c|}{ Stirling micro-CHP } \\
\hline Model & Whispergen EU1 \\
\hline Engine & 4 Cylinders double acting \\
\hline Electrical output & Stirling cycle \\
\hline Thermal output & Up to $7 \mathrm{~kW}$ \\
\hline Fuel consumption & $1.55 \mathrm{~m}^{3} / \mathrm{h}$ \\
\hline \multicolumn{2}{|c|}{ Solar thermal system } \\
\hline Collector model & Chromagen \\
\hline Collector area & $3.54 \mathrm{~m}^{2}$ \\
\hline Recommended flow & $45 \mathrm{l} / \mathrm{h} \cdot \mathrm{m}^{2}$ \\
\hline Maximum pressure & $10 \mathrm{bar}$ \\
\hline Storage tank capacity & 3001 \\
\hline \multicolumn{2}{|c|}{ Electronic DC/AC control } \\
\hline Inverter model & $\begin{array}{l}\text { Ingeteam Sun Storage 1play } \\
\text { 3TL }\end{array}$ \\
\hline \multicolumn{2}{|c|}{ Storage system connection } \\
\hline Voltage rank & $48-300 \mathrm{~V}$ \\
\hline Maximum charge/discharge & $50 \mathrm{~A}$ \\
\hline \multicolumn{2}{|c|}{ Photovoltaic connection } \\
\hline Voltage rank & $300-450 \mathrm{~V}$ \\
\hline Maximum intensity & $20 \mathrm{~A}$ \\
\hline \multicolumn{2}{|c|}{ Consumption connection } \\
\hline Maximum permanent power & $3000 \mathrm{~W}$ \\
\hline \multirow{2}{*}{\multicolumn{2}{|c|}{ Performance }} \\
\hline & \\
\hline Maximum efficiency & $95.5 \%$ \\
\hline Euroefficiency & $95 \%$ \\
\hline \multicolumn{2}{|c|}{ Accumulation system } \\
\hline Battery Model & LG Chem Resu 10 Li-Io \\
\hline Nominal Voltage & $51.8 \mathrm{~V}$ \\
\hline Voltage Range & $42.0-58.8 \mathrm{~V}$ \\
\hline Usable Energy & $8.8 \mathrm{kWh}$ \\
\hline Capacity & $189 \mathrm{Ah}$ \\
\hline \multicolumn{2}{|c|}{ Photovoltaic system } \\
\hline Nominal peak power & $3000 \mathrm{Wp}$ \\
\hline Nominal power of the modules & $245 \mathrm{Wp}$ \\
\hline Module efficiency & $15.04 \%$ \\
\hline Intensity of maximum power & $8.33 \mathrm{~A}$ \\
\hline Voltage of maximum power & $29.37 \mathrm{~V}$ \\
\hline \multicolumn{2}{|c|}{ Stirling micro-CHP } \\
\hline Model & Whispergen EU1 \\
\hline Engine & $\begin{array}{l}4 \text { Cylinders double acting } \\
\text { Stirling cycle }\end{array}$ \\
\hline Electrical output & Up to $1 \mathrm{~kW}$ \\
\hline Thermal output & Up to $7 \mathrm{~kW}$ \\
\hline Fuel consumption & $1.55 \mathrm{~m}^{3} / \mathrm{h}$ \\
\hline & \\
\hline Collector model & Chromagen \\
\hline Collector area & $3.54 \mathrm{~m}^{2}$ \\
\hline Recommended flow & $45 \mathrm{l} / \mathrm{h} \cdot \mathrm{m}^{2}$ \\
\hline Maximum pressure & $10 \mathrm{bar}$ \\
\hline Storage tank capacity & 3001 \\
\hline 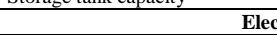 & trol \\
\hline Inverter model & $\begin{array}{l}\text { Ingeteam Sun Storage 1play } \\
\text { 3TL }\end{array}$ \\
\hline Storage sys & \\
\hline Voltage rank & $48-300 \mathrm{~V}$ \\
\hline Maximum charge/discharge & $50 \mathrm{~A}$ \\
\hline Photovol & \\
\hline Voltage rank & $300-450 \mathrm{~V}$ \\
\hline Maximum intensity & $20 \mathrm{~A}$ \\
\hline Consump & \\
\hline Maximum permanent power & $3000 \mathrm{~W}$ \\
\hline Maximum intensity & $13 \mathrm{~A}$ \\
\hline & \\
\hline Maximum efficiency & $95.5 \%$ \\
\hline Euroefficiency & $95 \%$ \\
\hline & \\
\hline Battery Model & LG Chem Resu 10 Li-Io \\
\hline Nominal Voltage & $51.8 \mathrm{~V}$ \\
\hline Voltage Range & $42.0-58.8 \mathrm{~V}$ \\
\hline Usable Energy & $8.8 \mathrm{kWh}$ \\
\hline Capacity & $189 \mathrm{Ah}$ \\
\hline & \\
\hline Nominal peak power & $3000 \mathrm{Wp}$ \\
\hline Modules nominal power & $245 \mathrm{Wp}$ \\
\hline Module efficiency & $15.04 \%$ \\
\hline Intensity of maximum power & $8.33 \mathrm{~A}$ \\
\hline Voltage of maximum power & $29.37 \mathrm{~V}$ \\
\hline
\end{tabular}


The system works according to an established flowchart. This flowchart allows optimizing the use of renewable sources and save gas consumption. In this way, the micro-CHP is an auxiliary source for both thermal and photovoltaic system.

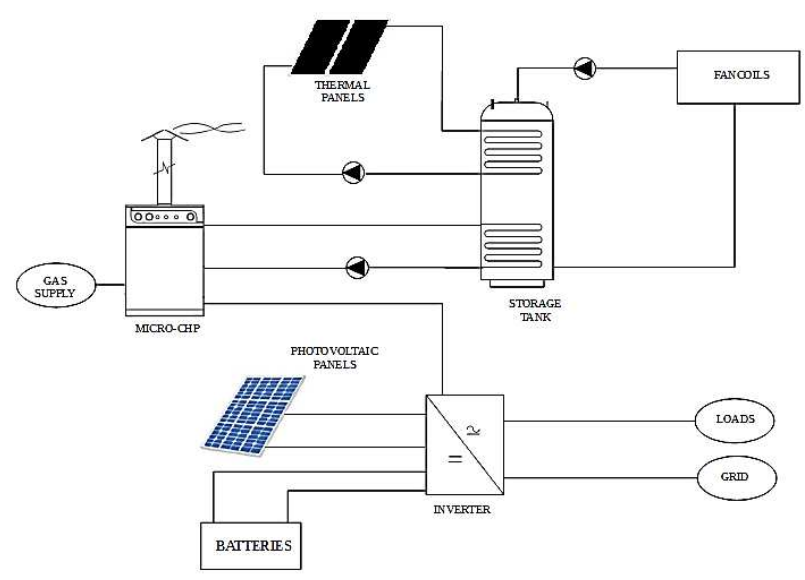

Fig.3 Diagram of the experimental system

\section{Result and discussion}

This work shows the results of the operation of the system described above for a sunny day (10/26/17) with an average daily temperature of $18.7^{\circ} \mathrm{C}$ and a daily irradiance of $6.7 \mathrm{kWh} / \mathrm{m}^{2}$.

Fig. 4 shows the theoretical and experimental hourly electricity consumption. By theoretical consumption, it indicates the consumption programmed in the system and the experimental consumption is the real consumption of the system on this day. A good agreement between both represented values is observed. The daily electricity demand was $17.5 \mathrm{kWh}$.

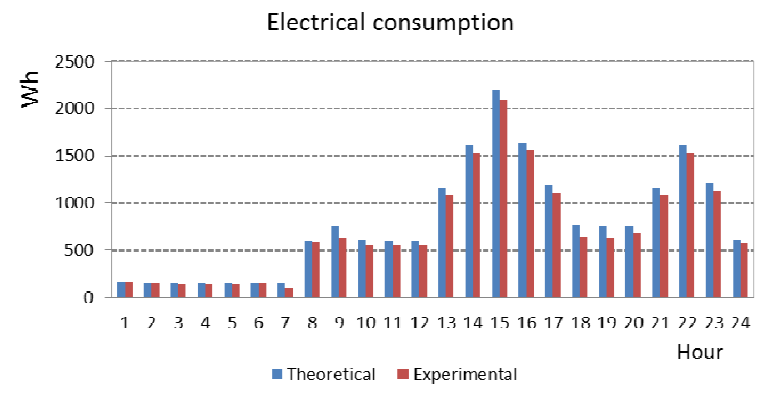

Fig.4. Daily electrical load profile

Fig.5 shows the daily electrical energy balance of the system. As can be observed, during sunny hours the consumption is covered directly by the photovoltaic system. If the PV production is greater than the consumption, the remaining energy charges the batteries and discharges them in the opposite case. When the battery reaches its maximum state of charge, the inverter regulates the point of maximum power of the photovoltaic generator to adapt the production to the required consumption (from 12:00 to 17:00 in this case). According to the irradiation received, the expected photovoltaic output was $15.9 \mathrm{kWh}$. However, the daily production has been only $11.1 \mathrm{kWh}$. This means that $30 \%$ of the solar resource has not been exploited.

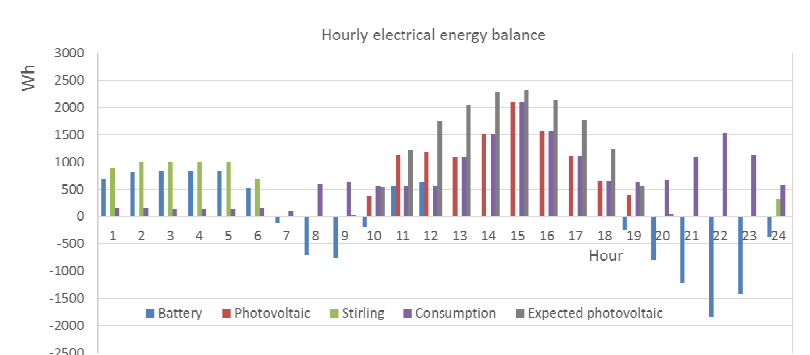

Fig. 5. Hourly electrical energy balance.

On the other hand, if the battery reaches its minimum state of charge and the photovoltaic system is not able to meet the demand, then the micro-CHP is started (from 23:00 to 6:00). In this case, the micro-CHP supplies electrical energy to the system until the battery reaches a state of charge of $80 \%$, and also produce corresponding thermal energy. The micro-CHP will then cease its production if the hot water demand is also satisfied. Negative battery values mean that the battery is being discharged and positive ones represent the charge.

Table II. Daily electrical energy balance

\begin{tabular}{ccc}
\hline & To consumption & To Battery \\
\hline Photovoltaic & $89 \%$ & $11 \%$ \\
Stirling & $21 \%$ & $79 \%$ \\
\hline \multicolumn{3}{c}{ Consumption } \\
\hline Photovoltaic & Stirling & Battery \\
$53 \%$ & $6 \%$ & $41 \%$ \\
\hline
\end{tabular}

Table II summarizes the daily energy flows of the system. As the table also shows, the photovoltaic system has directly covered $53 \%$ of the consumption, while the Stirling has been used mainly to charge the battery. This system has only directly supplied $6 \%$ of the consumption. The photovoltaic energy supplied directly to the load has been $89 \%$.

According to the diagram of figure 3 , all the thermal energy produced by both systems is accumulated in the thermal reservoir. In this way, the micro-CHP starts when the solar panels are not able to cover the thermal demand. If the temperature of the thermal tank reaches its maximum value and the micro-CHP is on, for electric necessities, the fan coils start to dissipate thermal energy independently of the established thermal consumption profile. As consequence, the programmed and experimental thermal demand curve present important discrepancies as can be seen in Fig.6. However, daily consumption has been lower than expected. The scheduled daily thermal consumption was $57 \mathrm{kWh}$ while the system has supplied $52 \mathrm{kWh}$. This happens due to a protection that restricts thermal consumption when the thermal reservoir is under $30^{\circ} \mathrm{C}$, in order to provide user's comfort. 


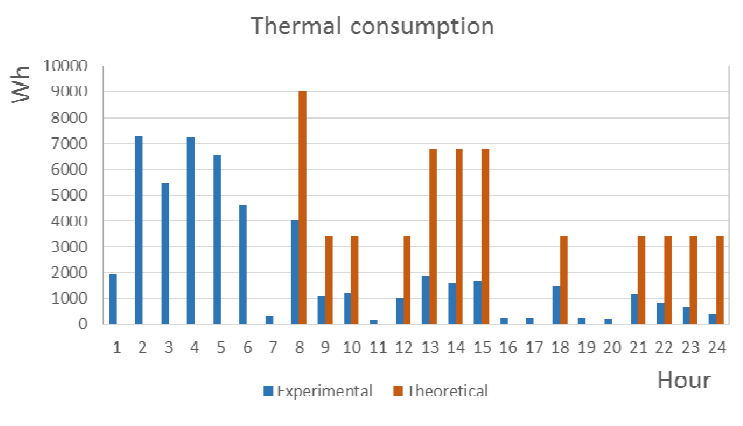

Fig.6. Daily thermal load profile

Table III. Daily thermal energy balance

\begin{tabular}{lc}
\hline \multicolumn{2}{c}{ Generated } \\
\hline Collectors & $17 \%$ \\
Stirling & $83 \%$ \\
\hline \multicolumn{2}{c}{ Use } \\
\hline Consumption & $92 \%$ \\
Accumulation & $8 \%$ \\
\hline
\end{tabular}

Fig.7 shows the daily thermal energy balance of the system, where it can be seen that the contribution of the thermal collectors is far less relevant as the Stirling unit (17\% of the first versus $83 \%$ of the second from the total generated energy, see Table III). Of this generated energy, the $92 \%$ has been used to supply the thermal loads and the remaining 8\% has been accumulated (see Table III). As it has been mentioned before, the total thermal consumption is greater than the generation. Thus, the temperature of the thermal reservoir logically decreases from $38,05{ }^{\circ} \mathrm{C}$ at the beginning of the day to $32,02^{\circ} \mathrm{C}$ at the end.

\section{Conclusions}

In this paper first operating data of a new microcogeneration system have been analysed. The study also shows the compatibility between these systems: Stirling engine-based micro-CHP (combined heat and power) and renewable solar energy: thermal and photovoltaic system to supply the energy demand of an isolated home

The results displayed show that it is possible to cover the energy demand of a house with these combined energy systems. However, only more detailed operation system study in different climatic conditions will be achievable to determine the solar systems' optimal size, in order to maximize their use and thus minimize gas consumption. The results show that while the size of the photovoltaic system seems adequate, for this demand profile, directly covering $53 \%$ of the electricity consumption. The solar thermal system should be increased due to it only covers $17 \%$ of the consumption. Furthermore, in both cases the strategy implemented does not allow the maximum use of the solar resource, but it rice a high level of optimization.

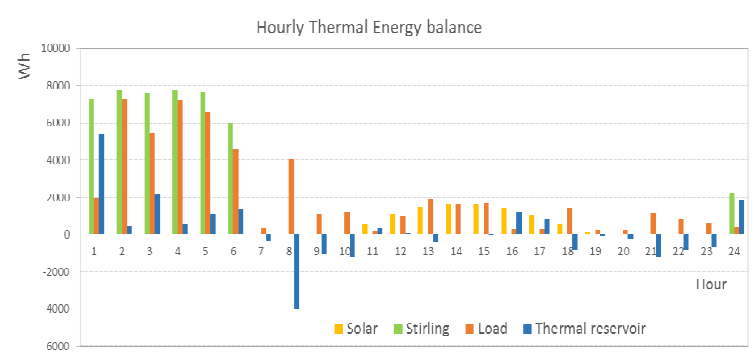

The main role of the storage's proper sizing (thermal and electrical) has been stated in order to achieve optimization in the system's operation.

Fig.7. Hourly thermal energy balance.

These results show the complexity of jointly controlling the different systems to satisfy the energy demand in isolated system.

\section{Acknowledgement}

This work has been supported by the University of Málaga, the Ministry of Education, Culture and Sport, and by the project P11-RNM-7115 of the Junta de Andalucía, Spain.

\section{References}

[1] I. Gonzalez-Pino; A. Campos-Celador; E. Perez-Iribarren et ál. Parametric study of the operational and economic feasibility of Stirling micro-cogeneration devices in Spain. 3rd International Conference Integration of Microgeneration and Related Energy Technologies in Buildings Naples (Italy) (2014) Applied Thermal Engineering, Vol. 71. N. 2 pg:821-829

[2] I. Gonzalez-Pino; E. Perez-Iribarren; A. Campos-Celador et ál. Influence of the regulation framework on the feasibility of a Stirling engine-based residential micro-CHP installation. ENERGY Vol : 84 Pg: 575-588 (2015)

[3] G. Valenti, P. Silva, N. Fergnani, G. Di Marcoberardino, S. Campanari y E.io Macchi. Experimental and numerical study of a micro-cogeneration Stirling engine for residential applications” Energy Procedia vol: 45 Pg: 1235-1244 (2014)

[4] T. Wakui and R. Yokoyama. Optimal structural design of residential cogeneration systems in consideration of their operating restrictions. Energy, vol:64 Pg:106-120 (2015)

[5] E. Malliotakis, G. Vourliotakis, R. Marin, A. Vicente, D. Giannopoulos, M. Founti, J. Zach and B. Starosielec. Performance monitoring of Stirling CHP units in an industrial district in Poland. International Stirling Engine Committee. Bilbao (2014)

[6] S. Karmacharya, G. Putrus, C.P. Underwood, K. Mahkamov, S. McDonald y A. Alexakis. Simulation of energy use in buildings with multiple micro-generators. Applied Thermal Engineering, Vol: 62 N: 2 Pg: 581-592 (2014) 
[7] L. Acevedo, J. Uche, A. Martinez, A.A. Bayod-Rújula, A. Del-Amo. Trigeneration for domestic purposes in isolated areas based on hybrid RES. International Conference on Renewable Energies and Power Quality (ICREPQ'17). Malaga (Spain). (2017)

[8] Jan Iwaszkiewicz, Jacek Perz, C. Jarosław. Mikielewicz. A practical approach to the cogeneration system for rural appliances International Conference on Renewable Energies and Power Quality (ICREPQ'09) Valencia (Spain). (2009)

[9] T. Schuster. Design and operation of a local cogeneration plant supplying a multi-family house. International Conference on Renewable Energies and Power Quality (ICREPQ'09) Valencia (Spain). (2009)

[10] M. Dondas, F. Alkhalil, P. Degobert, F. Colas and B. Robyns. Fuel consumption minimization of a cogeneration system multi machines associated with a photovoltaic. International Conference on Renewable Energies and Power Quality (ICREPQ’09) Valencia (Spain). (2009) 